\title{
Violencia contra la mujer: rol del ginecólogo en el combate de un flagelo que impacta negativamente en la salud integral de la mujer
}

Este 1 de abril un nuevo directorio asume al interior de la Sociedad Chilena de Obstetricia y Ginecología, por un período de dos años. Como sus predecesores, sus integrantes parten llenos de entusiasmo, motivaciones y dispuestos a asumir los desafíos que la sociedad nos demanda. Así también existe el compromiso, en cada uno de ellos, de continuar concretando las tareas iniciadas por sus antecesores e iniciar otras nuevas, todas acciones tendientes a velar por la salud integral de la mujer. Coincide con este nuevo período el octogésimo aniversario de la creación de nuestra Sociedad, evento que tendrá lugar en el año 2015. Es por ello que resulta relevante recordar los principios que motivaron su creación, así como también los desafíos que los fundadores se propusieron y por los cuales debemos continuar bregando.

La Sociedad de Obstetricia y Ginecología fue fundada en el año 1935, gracias a la visión del Dr. Carlos Monckeberg Bravo. Desde sus inicios, la premisa que nos rigió fue que como sociedad científica debíamos velar porque la atención en ginecología y obstetricia fuera de calidad, regida por el marco ético y en condiciones de equidad. Una atención médica integral, basada en lo mejor del conocimiento científico disponible para la época y donde la incorporación de los nuevos medios técnicos emergentes fuese ser oportuna, todo en pos de garantizar los mejores estándares de salud para la mujer. Así los fundadores establecieron una definición amplia de salud que no se limitaba al ámbito obstétrico, propio de una maternidad exitosa, sino que aborda las dimensiones psicológicas, afectivas, sociales, sexuales, culturales, etc., que posee toda mujer desde su nacimiento hasta su muerte. Los ginecólogos éramos y somos médicos consejeros, suerte de confidente de nuestras pacientes en las distintas etapas de su vida.
Ha sido en este marco de definiciones que nuestra Sociedad se ha transformado en un agente pro-activo en el diseño de las políticas públicas tendientes a mejorar los indicadores de salud de la mujer. A través de las décadas, diversos miembros de nuestra Sociedad han sido actores y líderes en la definición y ejecución de políticas destinadas a: reducir la mortalidad materna asociada al embarazo, parto y puerperio, promover la educación sexual en los distintos niveles sociales y etarios o defender los derechos reproductivos de la mujer. La labor ha sido exitosa en muchas de estas materias, sin embargo, para muchas de ellas queda mucho camino por recorrer y para otras ni siquiera hemos dado el primer paso.

Una de las tareas pendientes y que el directorio entrante pretende abordar durante su ejercicio es la violencia de género. Un flagelo que afecta a la mujer durante toda la vida y que tiene su expresión más grave en el femicidio.

Para muchos de los que lean esta editorial puede parecer un tema lejano e impropio del quehacer del especialista. Para otros les sonará más cercano y tal vez atingente, sólo por el conocimiento que se tuvo al leer del último caso de femicidio en las páginas del diario o por internet, mientras se esperaba la llegada de la siguiente paciente.

Sin embargo, el objetivo de esta editorial es poner en la palestra un tema poco conocido por la mayoría de nuestros colegas y que puede tener dimensiones impensadas. Este artículo busca además dar a conocer evidencias que muestra que se trata de un problema relevante para nuestra Sociedad y donde los ginecólogos y las matronas tenemos algo que decir y que hacer, más aún si mantenemos en mente un principio eje que motiva nuestro quehacer..... ser un médico consejero de cabecera. 
Para introducir el tema es necesario definir el problema: ¿qué es violencia de género? La violencia de género es un tipo de violencia física o psicológica ejercida contra cualquier persona sobre la base de su sexo o género. Es un problema que puede incluir asaltos o violaciones sexuales, prostitución forzada, explotación laboral, aborto selectivo en función del sexo, violencia física y sexual contra prostitutas, infanticidio femenino, tráfico de personas, violaciones sexuales durante período de guerra, ataques homofóbicos hacia personas o grupos de personas homosexuales, lesbianas, bisexuales y transgéneros, entre otros (1). Es un problema que por tanto afecta habitualmente a la mujer.

De hecho la Organización Mundial de la Salud (OMS) señala que "entre un $15 \%$ y un $71 \%$ de las mujeres han sufrido violencia física o sexual infligida por su pareja en algún momento de sus vidas". Dichos abusos, se dan en todas las clases sociales y en todos los niveles económicos y tienen graves consecuencias para la salud de la mujer, ya sea en forma de embarazos no deseados o de infecciones de transmisión sexual, depresión o enfermedades crónicas. Así también los reportes de este organismo indican que hasta un quinto de las mujeres refieren haber sufrido abusos sexuales antes de los 15 años (2).

El 20 de diciembre de 1993, las Naciones Unidas ratificó la declaración sobre la eliminación de la violencia contra la mujer, donde se afirmaba que esta violencia es un grave atentado a los derechos humanos de la mujer y la niña. En dicha declaración se definió como violencia contra la mujer "a todo acto de violencia basado en la pertenencia al sexo femenino que tenga o pueda tener como resultado un daño o sufrimiento físico, sexual o psicológico para la mujer, así como las amenazas de tales actos, la coacción o la privación arbitraria de la libertad, tanto si se producen en la vida pública como en la vida privada". Dichos actos de violencia se pueden producir al interior de la familia, en la comunidad y en el Estado. Estos actos presentan numerosas facetas que van desde la discriminación y el menosprecio hasta la agresión física o psicológica y el femicidio (3).

En el año 1995 tuvo lugar en Beijing, China, la Cuarta Conferencia sobre la Mujer, donde la humanidad se comprometió a velar por el derecho de toda mujer a disfrutar de los mejores estándares de salud física y mental que sean posibles de alcanzar. Principios cardinales que se establecieron para lograr el cumplimiento de dicho compromiso incluyeron: el evitar todo acto de discriminación e inequidad en términos de acceso a la nutrición, educación y atención en salud, la defensa de los derechos reproductivos pero también consideraba el establecimiento de políticas tendientes a evitar todo acto de violencia contra la mujer, entre otros. Chile estuvo presente en dicha ocasión y se hizo el compromiso como país de cumplir con las acciones propuestas tendientes a alcanzar dicho objetivo (4). Probablemente, en gran parte de dichas acciones nuestro país ha estado a la altura. Sin embargo, en términos de luchar contra la violencia de género aún queda mucho por hacer.

Independiente del interés que el tema nos genere, debiésemos preguntarnos si: ¿Alguna de mis pacientes habrá sido objeto de algún tipo de violencia de género?, o ¿cuántas veces pregunté por este tema cuando una paciente acudía a solicitar mi ayuda por un tema de sexualidad?, .... y si se preguntó, ¿qué puedo hacer yo? A fin de entender la relevancia en hacer estas preguntas y entender nuestro rol, es importante conocer algo de la realidad nacional en términos de violencia contra la mujer.

Primero debemos saber que uno de los problemas que existe para cuantificar la magnitud de este problema tanto en Chile como en el resto del mundo es que estos fenómenos son muy difíciles de dimensionar, a causa de la vulnerabilidad de las víctimas y el contexto íntimo en que estos hechos normalmente ocurren. Sólo se tiene un conocimiento parcial de su incidencia por medio del registro de casos policiales por violencia intrafamiliar y delitos sexuales.

La información más precisa proviene del registro de femicidios. El año 2011, 1873 mujeres murieron por causas externas, 40 de ellos correspondieron a casos de femicidio, equivalentes al $2 \%$ del total de muertes por esta causa. Una estadística que lamentablemente no ha cambiado drásticamente en los últimos años. De hecho, el 2013 se registraron otros 40 casos de femicidio, femicidios que afectaron a mujeres cuya edad oscilaba entre los 19 y 69 años $(5,6,7)$. La mayoría de ellas murieron a manos de su pareja o ex pareja y muchas de ellas dejaron hijos, cuyo cuidado debió ser asumido por familiares u organismos de asistencia y protección social. Muchas de ellas tuvieron episodios de violencia previa, de menor grado, y muchas de ellas pensaron que eso no volvería a pasar. Todos estos casos no solo tuvieron consecuencias individuales y familiares sino que conllevaron un impacto económico y social que en muchos casos debió ser asumido por el Estado (7).

Para algunos estos números pudiesen parecer poco relevantes desde la perspectiva pública, sin embargo, esto es la punta de un iceberg de violencia contra la mujer que tiene proporciones más grandes de las que uno pueda imaginar. 
En Chile, la encuesta nacional de victimización por violencia intrafamiliar y delitos sexuales (8) realizada el año 2012 (la anterior fue el 2007) mostró que un $31,9 \%$ de las mujeres entre 15 y 65 años, declaraba haber sufrido alguna forma de violencia familiar alguna vez en su vida. Al analizar las distintas formas de violencia, 30,7\% acusaba haber recibido violencia psicológica, $15,7 \%$ violencia física y $6,3 \%$ violencia sexual. Este estudio además mostró algunas características transversales entre aquellas mujeres que reconocieron haber sido agredidas, en cualquiera de sus formas. Era más frecuente en las mujeres residentes de algunas regiones (XV, VI y VIII), en niveles socioeconómicos más bajos (niveles $D$ y E), en mujeres jefas de hogar, o cuando había educación obligatoria incompleta (media en el caso de la violencia psicológica o física, básica en el caso de la violencia física o sexual) y más prevalente en ciertos grupos etarios (entre 36 y 45 años). Al analizar las características del agresor más del $50 \%$ de las veces correspondía a la pareja y muchas veces los episodios violentos se asociaban al consumo de estimulantes como alcohol (entre 20 y $40 \%$ ) y drogas (entre 7 y $11 \%$ )(8).

Debemos además conocer que hay al menos dos factores que dificultan dimensionar la magnitud del problema. El primero, la tendencia de las mujeres a minimizar la gravedad del hecho y no denunciar $(75 \%$ de las mujeres piensa que la situación se resolvió o que mejorará). En este sentido, el $87,1 \%$ no denuncia por diversas causas, entre las cuales destaca la vergüenza por la situación que la afecta $(40 \%)$ y la percepción de que no fue algo serio (12\%). El segundo factor que entorpece es el hecho de que pese a conocer sus derechos y de la existencia de legislación que les protege $(89 \%$ sabe de su existencia), la mayoría no desea recibir ayuda para enfrentar o resolver la situación (78\%). Una de las razones para explicar este contrasentido es que un $39 \%$ no está dispuesta a participar de un proceso judicial y tiene miedo de las consecuencias familiares y económicas que pueda tener su resolución (8).

Un hallazgo relevante de este estudio fue que las mujeres violentadas, sí desean recibir la ayuda $u$ orientación de un especialista en un centro. De hecho $67 \%$ muestró disposición a este tipo de apoyo, en particular a nivel primario, en los consultorios (8). Por tanto aquí toma relevancia la posibilidad de asistencia y labor educativa que pueda ejercer la matrona o el ginecólogo.

Lamentablemente tal oportunidad muchas veces no la aprovechamos. De hecho, el año 2011, el Dr. Aníbal Faundes, médico chileno radicado en Brasil y comisionado FIGO para la lucha contra este flagelo, en el contexto del XXXIII Congreso Chileno de Obstetricia y Ginecología, abordó esta problemática poniendo énfasis en el ámbito sexual. Dentro de los aspectos relevantes que abordo en su conferencia fueron las dificultades que tenemos los especialistas para lidiar con el tema. En dicha oportunidad el Dr. Faundes señaló y cito textual "es un problema que los médicos preferimos ignorar porque no sabemos actuar frente a él". De hecho sólo un 9 a $11 \%$ de los médicos en atención primaria consulta a sus pacientes por problemas de violencia doméstica (9). No preguntar sobre violencia doméstica puede conllevar perder la oportunidad de asistir o auxiliar a una víctima y por otra parte ignorar las consecuencias que tiene la violencia sexual en la mujer: trauma físico y psicológico, exposición y contagio de infecciones de transmisión sexual (ITS, ej. VIH), proceso inflamatorio pelviano e infertilidad, embarazo no deseado, aborto inseguro, provocado, vaginismo y depresión conducente al suicidio. En representación de FIGO, el Dr. Faundes recalcó que "es un deber de todo ginecólogo conocer sobre las normas de asistencia médica a toda mujer que ha sido víctima de violencia sexual". Dicha asistencia involucra la administración de medidas tendientes a proteger a la víctima (medidas médico-psicosociales) y a identificar al agresor (medidas médico-legales). Entre ellas se incluyen dar apoyo psicológico, prevenir un embarazo no deseado, prevenir y tratar precozmente una posible ITS, tratar posibles lesiones del tracto ginecológico, dar orientación legal (incentivar la denuncia) y asistencia social.

Los especialistas debemos conocer el problema, sus causas, los factores que contribuyen a estimular los actos violentos (ej. consumo de alcohol y drogas), de las estrategias educacionales que promueven una sexualidad sana y segura, de los derechos reproductivos de la mujer y de los programas gubernamentales que buscan prevenir actos violentos y dar asistencia oportuna a las víctimas, entre otros. Los estudios nos indican además que las estrategias más efectivas para reducir este flagelo se vinculan con promover políticas gubernamentales tendientes a educar a la población tanto femenina como masculina (10). Tal como quedó establecido en la conferencia de Beijing, dicha acción involucra capacitar a todo integrante del equipo de salud (4).

'Los ginecólogos debemos capacitarnos en estos temas a fin de influir no solo en nuestra paciente sino en su entorno'.

Como ginecólogos debemos conocer de: a) las normas, ordenanzas y reglamentos que velan por 
los derechos reproductivos de la mujer (i.e. normas nacionales sobre regulación de la fertilidad, norma y guía clínica de atención a víctimas de violencia sexual, norma sobre provisión de la anticoncepción de emergencia) $(11,12)$, b) los programas gubernamentales "Chile Acoge" para la prevención de la violencia intrafamiliar y atención de las víctimas (que incluye red de centros de asistencia y protección a la mujer, en particular para las que han sido objeto de violencia sexual), de "Educación temprana" para prevenir y detectar la violencia en sus inicios (educación dirigida a niños, adolescentes y adultos jóvenes) (13) y el de "La violencia tiene mil caras" (una guía para profesionales y comunicadores/as de medios de comunicación en violencia contra las mujeres) (14), c) de las campañas publicitarias como "me empelota la violencia contra la mujer" o "pololeo sin violencia" y d) la legislación vigente (ley no20.418 que fija normas sobre información, orientación y prestaciones en materia de regulación de la fertilidad, ley $n$ 으.066 sobre violencia intrafamiliar, entre otras) $(15,16)$.

El control ginecológico y obstétrico, donde: velamos por una maternidad y sexualidad segura, damos consejería sobre planificación familiar, hacemos prevención y detección de otras patologías médicas (ej. hipotiroidismo y obesidad), todo con el fin de buscar la salud integral de la mujer, debe además constituir una oportunidad para explorar si existen factores de riesgo o eventos que puedan conducir a violencia intrafamiliar. Debe ser una instancia en la cual aprovechemos de educar a todo el grupo familiar. $Y$ si tales eventos ya existen, dar consejería a las víctimas sobre las acciones a ejecutar a fin de evitar que la violencia se acreciente en el futuro. No hacerlo tiene como consecuencia daños físicos y psicológicos mayores, situación que como ginecólogos tal vez hemos escuchado o visto en nuestra consulta en el pasado, muchas veces de manera impávida o indiferente, siempre desde la vereda del frente.

Como Sociedad debemos asumir nuestro rol educador, capacitando a médicos y matronas, en especial a las nuevas generaciones de ginecólogos y obstetras, para que crucen la calle, se involucren y asistan o ayuden a toda mujer que pueda ser objeto potencial de violencia de género. Es por ello que este directorio asume el compromiso de comunicar y educar sobre este tema a través de todos los canales y medios con que cuenta (prensa, revistas, cursos y congresos, newsletter, Facebook, Twitter, canal SOCHOG, Youtube, entre otros) para así contribuir a reducir este flagelo que impacta negativamente en la salud integral de la mujer.

\section{Dr. Mauricio Cuello Fredes.}

Presidente.

Sociedad Chilena de Obstetricia y Ginecología.

\section{REFERENCIAS}

1. Kilmartin C, Allison J. Men's Violence Against Women: Theory, Research and Activism. Psychology Press 2007; pp 278.

2. Estudio multipaís de la OMS sobre salud de la mujer y violencia doméstica contra la mujer: Primeros resultados sobre prevalencia, eventos relativos a la salud y respuestas de las mujeres a dicha violencia, 2005. Disponible en: http://www.who.int/gender/violence/who_multicountry_study/summary_report/summaryreportSpanishlow.pdf

3. Declaración sobre la eliminación de la violencia contra la mujer. Resolución de la Asamblea General 48/104 del 20 de diciembre de 1993. Disponible en: http:// www.unhchr.ch/huridocda/huridoca.nsf/(Symbol)/A. RES.48.104.Sp?Opendocument

4. Women and Health. Fourth World Conference on Women, Beijing, China, 1995. Disponible en: http://www. un.org/womenwatch/daw/beijing/platform/health.htm

5. Defunciones por grupo de edad y grupo de causas, DEIS, 2011.

6. Número de femicidios según región año 2011. (Datos obtenidos del Programa VIF, Chile Acoge, SERNAM), 2011.

7. Femicidios 2013, datos obtenidos desde www.sernam.cl.

8. Encuesta Nacional de VIF y delitos sexuales, Ministerio del Interior, AdimarkGfK, 2013.

9. Rodríguez M, Bauer H, McLoughlin E, Grumbach K., Screening and intervention for intimate partner abuse: practices and attitudes of primary care physicians. JAMA 1999;282(5):468-74.

10. Barker G, Ricardo C, Nascimento M. Cómo hacer participar a los hombres y los niños en la lucha contra la inequidad de género en el ámbito de la salud: algunos datos probatorios obtenidos de los programas de intervención. OMS 2007. Disponible en: http://www. who.int/gender/documents/Men-SPAN.pdf

11. MINSAL. Normas nacionales sobre la regulación de la fertilidad. Disponible en: http://web.minsal.cl/portal/ url/item/795c63caff4ede9fe04001011f014bf2.pdf

12. MINSAL. Norma y guía clínica de atención a víctimas de violencia sexual. Disponible en: http://www.scielo. $\mathrm{cl} / \mathrm{pdf} / \mathrm{rchog} / \mathrm{v} 70 \mathrm{n} 1 / \mathrm{art11}$.pdf

13. Prevención de la Violencia Intrafamiliar: Programa Chile Acoge. Disponible en: http://www.sernam.cl/ descargas/plan_nacional_vif.pdf

14. La violencia tiene mil caras: Guía para Profesionales 
y Comunicadores/as de Medios de Comunicación en Violencia Contra las Mujeres. Disponible en: http:// estudios.sernam.cl/documentos/?eMjM3NTYzNw==La_Violencia_tiene_Mil_Caras:_Guia para_Profesionales_y_Comunicadores/ as_de_Medios_de_Comunicaci\%C3\%B3n_en_Violencia_Contra_las_Mujeres
15. Ley 20.418. Sobre conducta sexual de adolescentes; métodos de regulación de la fertilidad; derecho a la información; prevención del embarazo. Disponible en: http://www.mineduc.cl/usuarios/convivencia_escolar/ doc/201204161100160.ley_reg_fertilidad.pdf

16. Ley 20.066. Sobre violencia intrafamiliar. Disponible en: http://www.leychile.cl/Navegar?idNorma=242648 